\title{
Perbandingan Algoritma Backpropagation dan Learning Vector Quantization ( LVQ) dalam Pengenalan Pola Bangun Datar Geometri
}

\author{
Yeka Hendriyani ${ }^{*}$ \\ ${ }^{1}$ Jurusan Teknik Elektronika, Fakultas Teknik, Universitas Negeri Padang \\ *e-mail: yekahendriyani@ft.unp.ac.id
}

\begin{abstract}
Abstrak- Penelitian ini bertujuan untuk memberikan rekomendasi dari hasil perbandingan antara metode jaringan syaraf tiruan menggunakan metode backpropagation dan learning vector quantization ( $L V Q$ ) dalam melakukan pengenalan pola. Kedua metode ini sering digunakan untuk aplikasi pengenalan pola, karena kedua metode ini mampu mengelompokkan pola-pola ke dalam kelas-kelas pola dan termasuk kedalam metode pembelajaran terawasi (supervised learning). Dalam penelitian ini akan dibuktikan metode backpropagation dan LVQ mampu mengenali pola bentuk geometri bangun datar serta menunjukkan metode mana yang lebih baik dalam melakukan pengenalan pola. Implementasi metode backpropagation dan learning vector quantization (LVQ) menggunakan toolbox Matlab v8.5. Hal pertama yang dilakukan adalah melakukan proses pengolahan citra yaitu proses grayscalling dan thresholding untuk mendapatkan nilai binerisasi yang akan digunakan sebagai nilai input pada JST. Setelah itu nilai input akan diproses pada metode JST backpropagation dan learning vector quantization. Dari hasil implementasi pengujian kedua metode tersebut didapatkan bahwa algoritma backpropagation lebih baik dari learning vector quantization dalam pengenalan pola bangun datar geometri.
\end{abstract}

Kata Kunci : Kecerdasan Buatan, Jaringan Saraf Tiruan, Backpropagation, Learning Vector Quantization (LVQ), Bangun Datar

\begin{abstract}
This study aims to provide recommendation from the result of the comparison artificial neural network between backpropagation and learning vector quantization (LVQ) methods in pattern recognition. These methods are often used for pattern recognition applications, because these two methods are able to grouping patterns into pattern classes and included in supervised learning methods. In this study will be proven backpropagation and LVQ are able to recognize the pattern of two-dimentional figure geometry shapes and show which method better in pattern recognition. Implementation of backpropagation and learning vector quantization (LVQ) is using Matlab v8.5. The first thing is doing image processing process there is grayscalling and thresholding process to get the bineryzation value that will be used as the input value on ANN. After that the input value will be processed in ANN method backpropagation and LVQ. From the result of the implementation of the testing these methods backpropagation is better learning vector quantization than learning vector quantization in the recognition of geometry shape patterns.
\end{abstract}

Keywords : Artificial intelligence, Artificial neural network, Backpropagation, Learning Vector Quantization, Geometry Shapes 


\section{Pendahuluan}

Jaringan saraf tiruan adalah cabang kecerdasan buatan (AI) yang didefinisikan sebagai sistem pemrosesan informasi, yang dirancang dengan meniru cara kerja otak manusia dalam menyelesaikan masalah dengan melakukan proses pembelajaran melalui perubahan bobot sinaptik [1] . Jaringan saraf tiruan yang bekerja seperti jaringan saraf manusia memiliki kemampuan luar biasa dalam menyelesaikan masalah. Karena jaringan syaraf tiruan dapat mempelajari data yang disediakan, mampu memproses input data sehingga dapat membuat organisasi sendiri dari informasi yang diterimanya selama pembelajaran [2]. Banyak peneliti telah membuktikan kehandalan dari metode jaringan saraf tiruan dan telah berhasil mengimplementasikan di berbagai bidang seperti pengendali robot [3], diagnosis klasifikasi malaria [4], peramalan beban listrik [5], Pemodelan prediksi air sungai [6] dan di bidang pendidikan seperti penelitian yang telah dibuktikan [7] dalam mengevaluasi waktu belajar e-learning dan [8] dalam tantangan belajar bahasa asaing dan sistem pendukung keputusan untuk penjurusan siswa [9].

Kemampuan luar biasa yang dimiliki oleh jaringan saraf tiruan ini dapat diterapkan pada komputer dan dikembangkan untuk berbagai cara, dalam mengenali dan mengidentifikasi pola [10]. Oleh karena itu, penerapan jaringan saraf tiruan telah banyak diterapkan pada berbagai sistem untuk membantu kinerja manusia seperti dalam pengenalan pola atau klasifikasi data. Ada 2 jenis metode pembelajaran dalam jaringan saraf tiruan, yaitu pembelajaran terawasi dan tidak terawasi. Untuk melakukan pengenalan pola, pembelajaran yang diawasi lebih cocok karena menggunakan target keluaran. Ada metode besar untuk melakukan pola, termasuk pembelajaran yang diawasi untuk metode pengenalan pola adalah metode backpropagation dan Learning Vector Quantization ( $L V Q)$. $L V Q$ adalah metode klasifikasi dimana jumlah setiap unit output merepresentasikan atau mewakili sebuah kelas[11].

Geometri adalah cabang matematika yang memberikan pemahaman tentang beberapa bidang atau poin seperti angka dua dimensi hingga tiga angka dimensi. Figur tiga dimensi adalah konstruk geometris yang membentuk ruang sehingga memiliki volume sedangkan figur dua dimensi adalah struktur geometris datar [12]. [13] Menggambarkan geometri sebagai representasi abstrak paling mendasar dari dunia nyata. Karena bidang geometri ini memiliki berbagai jenis objek fisik di setiap struktur geometris. Oleh karena itu, pengenalan pola dapat dilakukan untuk mengenali bentuk objek dalam geometri, terutama bentuk datar dan diterapkan sebagai objek pengujian, hasil akurasi pengenalan pola menggunakan jaringan saraf tiruan. Dalam artikel ini akan ditampilkan hasil analisis pengenalan pola bentuk geometri bangun datar menggunakan metode Backpropagation, Learning Vector Quantization (LVQ) dan perbandingan hasil dari kedua algoritma tersebut.

\section{MetodA}

Sesuai dengan keterbatasan masalah dan rumusan masalah serta tujuan penelitian yang telah dijelaskan, maka penelitian ini adalah penelitian sesuai dengan tujuan yang lebih diarahkan pada penelitian terapan. Penelitian terapan adalah penelitian yang diarahkan untuk mendapatkan informasi yang dapat digunakan untuk memecahkan masalah [14]. Penelitian ini dilakukan untuk memperoleh informasi dari dua metode yang akan diuji, yaitu metode backpropagation dan Learning Vector Quantization ( $L V Q)$ yang akan lebih baik dalam pengenalan pola bangun datar geometri.

\section{Data Analysis}

Percobaan penelitian dilakukan analisis akurasi dari dua metode, Backpropagation dan Learning Vector Quantization ( $L V Q)$ dengan proses sebagai berikut:

a. Penelitian dan pengujian terhadap metode backpropagation dan learning vector quantization menggunakan toolbox Matlab versi 8.5.

b. Melakukan pengolahan citra bentuk geometri bidang datar pada matlab yaitu proses grayscaling, thresholding dan merubah citra tersebut menjadi biner yang akan menjadi nilai inputan dalam proses pembelajaran pada 
masing-masing metode. Dalam proses grayscaling cluster varian dianggap sebagai indeks penting untuk keseragaman [15].

c. Membuat jaringan backpropagation pada matlab akan menggunakan instruksi newff dan pada jaringan learning vector quantization akan menggunakan instruksi lvqnet.

d. Menentukan parameter pada masing-masing metode untuk melakukan proses pembelajaran pada pengenalan pola dalam menggunakan metode-metode tersebut.

e. Mengukur waktu dalam pelatihan pengenalan pola pada masing-masing metode.

f. Mengetahui berapa banyak iterasi dalam pengenalan pola dengan parameter yang ditentukan pada masing-masing metode.

g. Melakukan proses pengujian terhadap masing-masing metode.

h. Mengukur hasil akurasi pengenalan pola pada masing - masing metode.

Setelah mendapatkan data dari masing - masing metode, lalu hasil dari data tersebut digunakan sebagai hasil pengujian antar kedua metode tersebut dan dibentuk tabel-tabel untuk diambil kesimpulannya.

\section{HASIL DAN PEMBAHASAN}

Dalam melakukan pengolahan data, metode yang akan diuji digunakan program Matlab dan perhitungan data numerik dibantu dengan software Microsoft Excel.

\section{A. Proses Pengolahan Citra}

Dalam melakukan proses pengolahan citra atau proses ektraksi ciri citra untuk pengenalan bentuk geometri bidang datar akan melalui proses greyscalling, thresholding hingga binerisasi.

\section{a. Grayscalling}

Data yang dimasukkan adalah gambar jenis RGB. Untuk membuatnya menjadi gambar biner, jenis gambar RGB berubah menjadi gambar skala abu-abu untuk memudahkan pemrosesan gambar, seperti gambar 1.

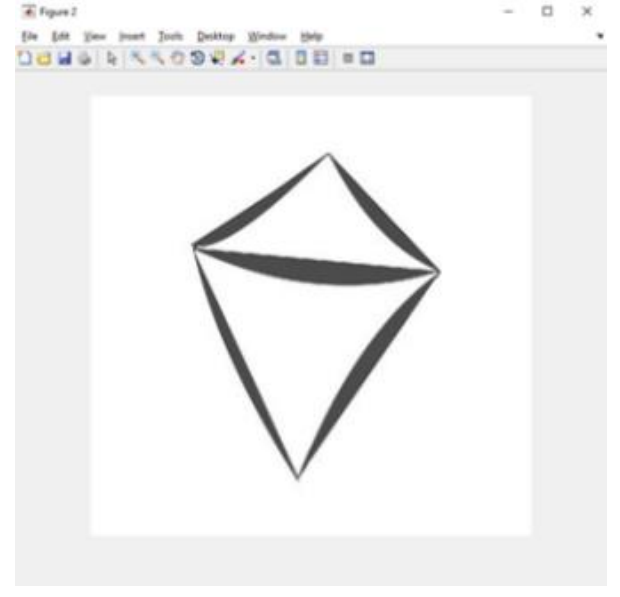

Gambar 1. Hasil Grayscalling

\section{b. Thresholding}

Proses ini adalah untuk mengubah gambar skala abu-abu menjadi skala B/W(skala hitam dan putih). Pada proses threshold ini menggunakan proses thresholding dengan metode 'graythresh' atau metode otsu. Teknik thresholding ini telah terbukti sangat handal dan dengan penjelasan yang detile [16]. Hasil proses thresholding dapat dilihat pada gambar 2.

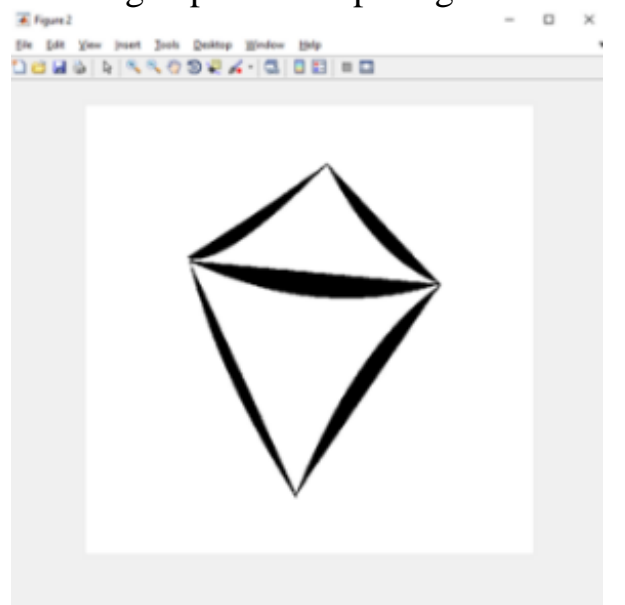

Gambar 2. Hasil Proses Thresholding

Setelah proses ambang dilakukan, untuk menemukan struktur gambar yang lebih kecil dari latar belakang. Kemudian fungsi unclementment() digunakan, sehingga nilai piksel yang ingin Anda kenali memiliki nilai dan latar belakang gambar yang lebih tinggi. Langkah selanjutnya menggunakan operasi penutupan dan pengisian lubang morfologi dan menghilangkan kebisingan pada objek. 


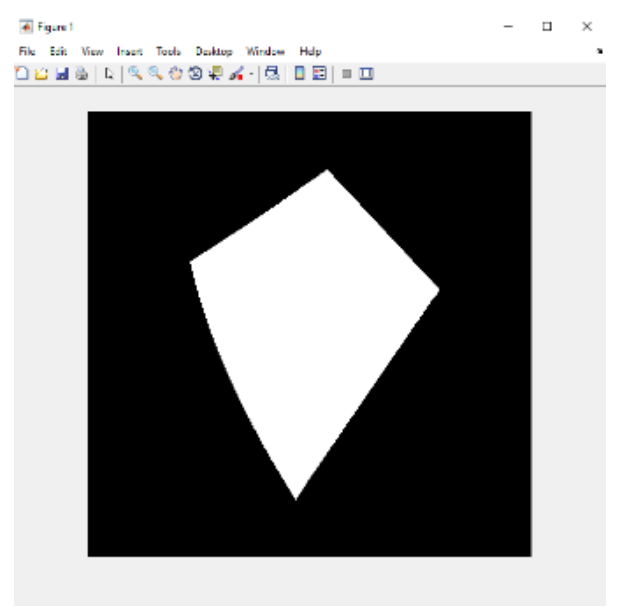

Gambar 3. Hasil Estraksi Fitur Gambar

Dari proses ekstraksi fitur gambar pada semua data pelatihan, metrik vektor dan nilai eksentrisitas dihasilkan yang mengandung nilai biner yang memiliki kisaran nilai 0 hingga 1. Nilai metrik vektor dan eksentrisitas akan digunakan sebagai nilai input untuk proses jaringan saraf tiruan dalam pengenalan pola menggunakan metode backpropagation and learning vector quantization.

\section{B. Implementation Artificial Neural Network}

Tabel 1. Parameter Algoritma untuk Pengujian

\begin{tabular}{ll} 
Parameter & Value \\
\hline Epoch & $100,250,500$ \\
\hline Learning Rate & $-, 0.01,0.025$. \\
\hline
\end{tabular}

Note : - tidak didefinisikan

\section{a. Metode Backpropagation}

Pengujian Data tentang Backpropagation

Tabel 2. Hasil Pelatihan Backpropation

\begin{tabular}{llllll}
\hline No & A & B & C & D & E \\
\hline 1 & - & 100 & 34 & 8 & $80.95 \%$ \\
2 & 0.01 & 100 & 28 & 14 & $66.67 \%$ \\
3 & 0.025 & 100 & 33 & 9 & $78.57 \%$ \\
4 & - & 250 & 26 & 16 & $61.90 \%$ \\
5 & 0.01 & 250 & 28 & 14 & $66.67 \%$ \\
6 & 0.025 & 250 & 27 & 15 & $64.29 \%$ \\
7 & - & 500 & 37 & 5 & $88.10 \%$ \\
8 & 0.01 & 500 & 29 & 13 & $69.05 \%$ \\
9 & 0.025 & 500 & 25 & 17 & $59.52 \%$ \\
\hline
\end{tabular}

\section{Note :}

A : Learning Rate

B : poch

C : Image Recognized

D : Image Unrecognized

E : Accuration.

Berdasarkan tabel 2, kombinasi nomor parameter 7 adalah akurasi terbaik untuk proses pengujian backpropagation, dengan hasil sebesar $88.10 \%$ sedangkan hasil terendah pada nomor 9 yaitu $59.52 \%$.

Tabel 3. Hasil Pengujian Metode Backpropogation

\begin{tabular}{llllll}
\hline No & A & B & C & D & E \\
\hline 1 & - & 100 & 29 & 6 & $82.86 \%$ \\
2 & 0.01 & 100 & 23 & 12 & $65.71 \%$ \\
3 & 0.025 & 100 & 27 & 8 & $77.14 \%$ \\
4 & - & 250 & 21 & 14 & $60.00 \%$ \\
5 & 0.01 & 250 & 23 & 12 & $65.71 \%$ \\
6 & 0.025 & 250 & 22 & 13 & $62.86 \%$ \\
7 & - & 500 & 32 & 3 & $91.43 \%$ \\
8 & 0.01 & 500 & 23 & 12 & $65.71 \%$ \\
9 & 0.025 & 500 & 12 & 23 & $34.29 \%$ \\
\hline
\end{tabular}

Berdasarkan tabel 3 proses pengujian menggunakan 35 citra data uji, hasil akurasi pengujian terbaik didapatkan pada parameter 7 yaitu sebesar $91.43 \%$ dan mengenal sebanyak 32 citra.

\section{b. Learning vector quantization}

Data Testing Learning vector quantization

Tabel 4. Hasil Pelatihan LVQ

\begin{tabular}{llllll}
\hline No & A & B & C & D & E \\
\hline 1 & - & 100 & 24 & 18 & $57.14 \%$ \\
2 & 0.01 & 100 & 29 & 13 & $69.05 \%$ \\
3 & 0.025 & 100 & 26 & 16 & $61.90 \%$ \\
4 & - & 250 & 29 & 13 & $69.05 \%$ \\
5 & 0.01 & 250 & 23 & 19 & $54.76 \%$ \\
6 & 0.025 & 250 & 29 & 13 & $69.05 \%$ \\
7 & - & 500 & 29 & 13 & $69.05 \%$ \\
8 & 0.01 & 500 & 29 & 13 & $69.05 \%$ \\
9 & 0.025 & 500 & 25 & 17 & $59.52 \%$ \\
\hline
\end{tabular}

Berdasarkan tabel 4 diatas dapat dilihat hasil akurasi pelatihan terbaik pada epoch 100, 250 dan 500 didapatkan pada parameter 2,4,6,7 dan 8 yaitu sebesar $69.05 \%$ dengan waktu pelatihan selama 27 detik dan mengenali citra sebanyak 29 citra dari 42 data latih citra yang ada. 
Tabel 5. Hasil Pengujian LVQ

\begin{tabular}{llllll}
\hline No & A & B & C & D & E \\
\hline 1 & - & 100 & 17 & 18 & $48.57 \%$ \\
2 & 0.01 & 100 & 22 & 13 & $62.86 \%$ \\
3 & 0.025 & 100 & 16 & 19 & $45.71 \%$ \\
4 & - & 250 & 23 & 12 & $65.71 \%$ \\
5 & 0.01 & 250 & 15 & 20 & $42.86 \%$ \\
6 & 0.025 & 250 & 23 & 12 & $65.71 \%$ \\
7 & - & 500 & 23 & 12 & $65.71 \%$ \\
8 & 0.01 & 500 & 23 & 12 & $65.71 \%$ \\
9 & 0.025 & 500 & 19 & 16 & $54.29 \%$ \\
\hline
\end{tabular}

Berdasarkan hasil penelitian pada proses pelatihan dan pengujian metode LVQ dengan maksimum perulangan (epoch) sebesar 100 epoch, maka dapat dilihat arsitektur jaringan yang optimal pada nilai epoch ini untuk pengujian metode LVQ 65,71 pada parameter 4, 6,7 dan 8 .

\section{DISKUSI DAN TEMUAN}

Berdasarkan tabel 1, 2, 3 dan 4 dalam melakukan pengenalan pola citra bentuk geometri bidang datar penerapan metode backpropagation dan LVQ pada beberapa parameter uji, bahwa rata-rata total hasil metode backpropagation lebih unggul daripada metode kuantisasi vektor pembelajaran yaitu 67,30\% sedangkan untuk LVQ adalah 57,46\%. Berikut ini dalam tabel 5 akan membandingkan hasil perbandingan pengujian akurasi optimal dalam kedua metode.

Tabel 6. Hasil Perbandingan Pengujian Terhadap Kedua Metode

\begin{tabular}{|c|c|c|c|c|c|c|c|c|c|c|}
\hline \multirow{3}{*}{ No } & \multirow{3}{*}{ Epoch } & \multirow{3}{*}{ Parameter } & \multicolumn{8}{|c|}{ Method } \\
\hline & & & \multicolumn{4}{|c|}{ Backpropagation } & \multicolumn{4}{|c|}{ LVQ } \\
\hline & & & $\operatorname{lr}$ & $\begin{array}{c}\text { Image } \\
\text { Recognized }\end{array}$ & $\begin{array}{c}\text { Accuration } \\
(\%)\end{array}$ & Average & $\operatorname{lr}$ & $\begin{array}{c}\text { Image } \\
\text { Recognized }\end{array}$ & $\begin{array}{c}\text { Accuration } \\
(\%)\end{array}$ & Average \\
\hline \multirow{3}{*}{1} & \multirow{3}{*}{100} & 1 & - & 29 & $82.86 \%$ & \multirow{3}{*}{$75.24 \%$} & default & 17 & 48.57 & \multirow{3}{*}{$52.38 \%$} \\
\hline & & 2 & 0.01 & 23 & $65.71 \%$ & & 0.01 & 22 & 62.71 & \\
\hline & & 3 & 0.025 & 27 & $77.14 \%$ & & 0.025 & 16 & 45.71 & \\
\hline \multirow{3}{*}{2} & \multirow{3}{*}{250} & 1 & - & 21 & $60.00 \%$ & \multirow{3}{*}{$62.86 \%$} & default & 23 & 65.71 & \multirow{3}{*}{$58.09 \%$} \\
\hline & & 2 & 0.01 & 23 & $65.71 \%$ & & 0.01 & 15 & 42.86 & \\
\hline & & 3 & 0.025 & 22 & $62.86 \%$ & & 0.025 & 23 & 65.71 & \\
\hline \multirow{3}{*}{3} & \multirow{3}{*}{500} & 1 & - & 32 & $91.43 \%$ & \multirow{3}{*}{$63.81 \%$} & default & 23 & 65.71 & \multirow{3}{*}{$61.90 \%$} \\
\hline & & 2 & 0.01 & 23 & $65.71 \%$ & & 0.01 & 23 & 65.71 & \\
\hline & & 3 & 0.025 & 12 & $34.29 \%$ & & 0.025 & 10 & 54.29 & \\
\hline \multicolumn{6}{|c|}{ Total Rata-rata } & $67.30 \%$ & \multicolumn{3}{|c|}{ Total Rata-rata } & $57.46 \%$ \\
\hline
\end{tabular}

Tabel 7. Hasil Definisi Ketepatan Tes Terbaik untuk Kedua Metode

\begin{tabular}{|c|c|c|c|c|c|c|c|}
\hline \multirow[t]{3}{*}{ No } & \multirow[t]{3}{*}{ Epoch } & \multicolumn{6}{|l|}{ Method } \\
\hline & & \multicolumn{3}{|c|}{ Backpropagation } & \multicolumn{3}{|l|}{ LVQ } \\
\hline & & Parameter & $\begin{array}{l}\text { Image } \\
\text { Recognized }\end{array}$ & $\begin{array}{l}\text { Accuration } \\
(\%)\end{array}$ & Parameter & $\begin{array}{l}\text { Image } \\
\text { Recognized }\end{array}$ & $\begin{array}{l}\text { Accuration } \\
(\%)\end{array}$ \\
\hline 1 & 100 & 1 & 29 & $82.86 \%$ & 2 & 22 & $62.86 \%$ \\
\hline 2 & 250 & 2 & 23 & $65.71 \%$ & 1 & 23 & $65.71 \%$ \\
\hline 3 & 500 & $\begin{array}{l}1 \\
\text { Average }\end{array}$ & 32 & $\begin{array}{l}91.43 \% \\
80.00 \%\end{array}$ & $\begin{array}{l}1 \\
\text { Average }\end{array}$ & 23 & $\begin{array}{l}65.71 \% \\
64.76 \%\end{array}$ \\
\hline
\end{tabular}

Berdasarkan tabel 7 dapat dilihat dari semua hasil pengujian terbaik dari 3 parameter yang ditentukan, rata-rata menghasilkan akurasi yang optimal pada parameter pertama dan kedua, yaitu parameter pertama menggunakan nilai learning rate $=$ default (tidak ditentukan) dan paremeter kedua menggunakan nilai learning rate $=0.01$. Dilihat dari hasil perbandingan penelitian hasil akurasi yang optimal, metode backpropagation lebih baik dalam melakukan pengenalan pola citra bentuk geometri bidang datar yaitu memiliki rata-rata pengujian sebesar $80 \%$ daripada metode LVQ hanya dapat melakukan rata-rata pengujian sebesar $64.76 \%$. Backpropagation mampu mengenali hingga akurasi $91.43 \%$ atau dapat mengenali 32 citra uji dari 35 citra uji yang ada pada nilai epoch sebanyak 500. 


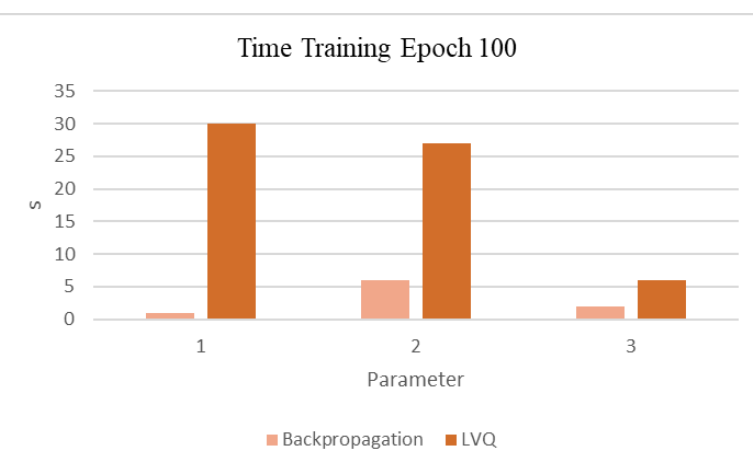

Gambar 4. Bagan Perbandingan Waktu Pelatihan di Epoch 100

Berdasarkan gambar 4 dapat dilihat bahwa metode $L V Q$ membutuhkan waktu yang lama dalam melakukan pelatihan. Karena metode $L V Q$ dalam melakukan pelatihan (training) akan melakukan iterasi sebanyak nilai epoch yang ditentukan sehingga membutuhkan waktu yang lebih lama dibandingkan metode backpropagation. Metode backpropagation melakukan pelatihan sampai nilai sudah mencapai target yang diinginkan dan akan terhenti, karena jika tetap dilakukan iterasi maka akan mendapatkan hasil yang sama. Grafik perbandingan waktu pelatihan pada epoch 250 dan 500 dapat dilihat pada gambar 5.

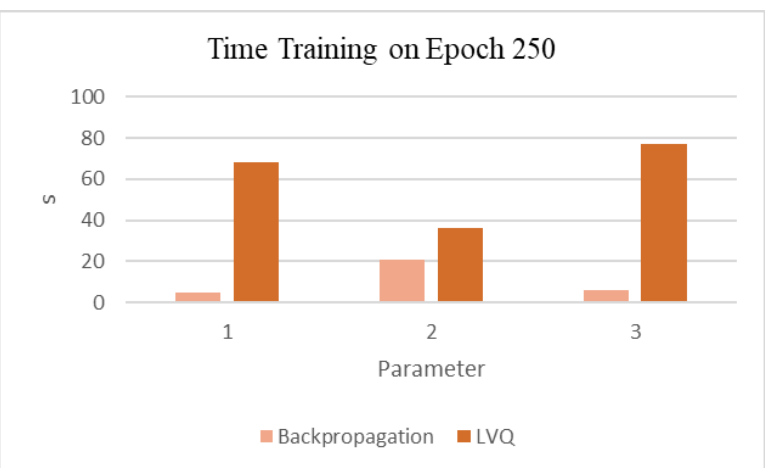

Gambar 5. Bagan Perbandingan Waktu Pelatihan di Epoch 250

Pada gambar 5 dapat dilihat grafik pada epoch 250 metode $L V Q$ melakukan pelatihan lebih lama dibandingkan dengan metode backpropagation.

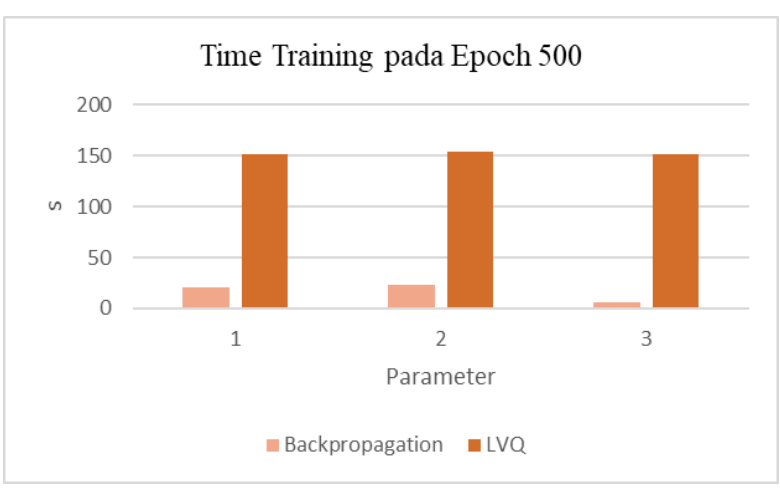

Gambar 6. Bagan Perbandingan Waktu Pelatihan di Epoch 500

Gambar 6 menunjukkan bahwa pada epoch 500 metode LVQ melakukan pelatihan yang lama dibandingkan dengan waktu pelatihan metode backpropagation.

Dari hasil pengujian dan perbandingan terhadapat kedua metode ini yaitu backpropagation dan learning vector quantization, dapat dilihat bahwa dalam melakukan penelitian ini untuk melakukan pengenalan pola citra bentuk geomteri bidang datar metode yang unggul untuk melakukan pengenalan pola citra ini adalah menggunakan metode jaringan syaraf tiruan backpropagation. Karena metode ini lebih unggul dalam hasil akurasi maupun waktu proses pelatihan. Hasil akurasi pengujian tertinggi pada metode backpropagation sebesar $91.43 \%$ dan mengenali citra sebanyak 32 citra uji dan 35 citra uji yang ada sedangkan metode $L V Q$ akurasi pengujian paling optimal hanya sebesar $65.71 \%$. Untuk waktu pelatihan dapat dilihat gambar 4 sampai gambar 6 bahwa $L V Q$ melakukan proses training lebih lama dibandingkan metode backpropagation karena metode LVQ melakukan iterasi sebanyak nilai maksimum (epoch) yang ditentukan.

\section{KESIMPULAN}

Dari hasil penelitian ini, pembuatan sistem, pengujian dan analisis hasil pengenalan pola bentuk geometri angka dua dimensi menggunakan jaringan saraf tiruan antara backpropagation dan pembelajaran vektor kuantisasi, maka kesimpulan berikut diperoleh:

Metode backpropagation dan learning vector quantization (LVQ) mampu melakukan pengenalan pola pada bentuk geometri dua dimensi . Perbandingan dua metode jaringan saraf tiruan antara backpropagation dan learning vector quantization dapat dilihat dari hasil perbandingan bahwa metode backpropagation lebih mampu mengenali pola gambar bentuk geometri bentuk dua-dimensi daripada kuantisasi vektor 
pembelajaran (Metode LVQ). Karena dalam melakukan pengenalan pola gambar ini dengan parameter pengujian yang ditentukan backpropagation mendapatkan rata-rata hasil pengujian akurasi yang lebih tinggi dibanding pembelajaran learning vector quantization $(L V Q)$. Tingkat kesesuaian dan akurasi pengujian pengenalan pola gambar dalam bangun datar geometri dua dimensi pada kombinasi parameter yang digunakan dalam proses pelatihan. Waktu pelatihan backpropagation juga lebih cepat daripada metode kuantisasi vektor pembelajaran, karena metode LVQ berulang sebanyak nilai zaman maksimum yang ditentukan sedangkan untuk iterasi backpropagation akan berhenti jika memiliki nilai MSE terbaik dan nilai output telah mencapai target, jika loop yang dikembalikan tidak berubah lagi.

\section{DAFTAR PUSTAKa}

[1] Halim, M. I., Dwi, A., T, A. N. S., \& T, C. S. S. (2017). Analisis Sentimen Menggunakan Metode Learning Vector Quantization Sentiment Analysis Using Learning Vector Quantization Method, 4(2), 2283-2292..

[2] Fathia, S., 2013. Penerapan Jaringan Syaraf Tiruan Dalam Pengenalan Tulisan Tangan Huruf Korea (Hangul) Menggunakan Metode Propagasi Balik. Skripsi, Fakultas Ilmu Komputer Universitas Dian Nuswantoro. Semarang

[3] Degrave, J., Hermans, M., Dambre, J., \& wyffels, F. (2019). A differentiable physics engine for deep learning in robotics. Frontiers in Neurorobotics, doi:http://dx.doi.org/10.3389/fnbot.2019.0000 6

[4] Ross, N. E., Pritchard, C. J., Rubin, D. M., \& Dusé, A.,G. (2006). Automated image processing method for the diagnosis and classification of malaria on thin blood smears. Medical and Biological Engineering and Computing, 44(5), 427-36. doi:http://dx.doi.org/10.1007/s11517-0060044-2

[5] Sajjad, A. H., Naqvi, S. R., Akram, T., \& Kamran, M. (2017). Prediction of critical currents for a diluted square lattice using artificial neural networks. Applied Sciences, 7(3), 238. doi:http://dx.doi.org/10.3390/app7030238

[6] Parmar, K. S., \& Bhardwaj, R. (2015). River water prediction modeling using neural networks, fuzzy and wavelet coupled model. Water Resources Management, 29(1),
17-33. doi:http://dx.doi.org/10.1007/s11269014-0824-7

[7] Kartal, E. (2019). The artificial neural network modeling of language learning challenges of french-speaking students learning Turkish as a foreign language: The case of france. Educational Sciences: Theory and Practice, 19(1), 55-77. https://doi.org/10.12738/estp.2019.1.0264

[8] Mustafa, H. M. H., Tourkia, F. Ben, \& Ramadan, R. M. (2017). An Overview on Evaluation of E-Learning/Training Response Time Considering Artificial Neural Networks Modeling. Journal of Education and ELearning Research, 4(2), 46-62. https://doi.org/10.20448/journal.509.2017.42. 46.62

[9] Rachman, B., Hendriyani, Y., Budayawan, K.(2016).Perancangan dan Implementasi Sistem Pendukung Keputusan Untuk Penjurusan Siswa Menggunakan Metode Jaringan Saraf Tiruan Studi Kasus di MAN 2 Padang Panjang. Jurnal Vokasional Teknik Elektronika dan Informatika, 4(1)

[10] Gustina, S., Fadlil, A., \& Umar, R. (2016). Identifikasi Tanaman Kamboja menggunakan Ekstraksi Ciri Citra Daun dan Jaringan Syaraf Tiruan, 2(1), 128-132.

[11] Halim, M. I., Dwi, A., T, A. N. S., \& T, C. S. S. (2017). Analisis Sentimen Menggunakan Metode Learning Vector Quantization Sentiment Analysis Using Learning Vector Quantization Method, 4(2), 2283-2292.

[12] Ketutsuratni. 2012. Bangun Datar Dan Bangun Ruang.

https://mahasuryaa.wordpress.com/2012/01/01 /bangun-ruang-dan-bangun-datar/ diakses 10 April 2018.

[13] Hilton, P., \& Pedersen, J. (2004). The changing shape of geometry: Celebrating a century of geometry and geometry teaching. American Scientist, 92(1), 91-92. Retrieved from https://search.proquest.com/docview/2152588 07 ? accountid $=38628$

[14] Jogiyanto. H.M. 2008. Metodologi Penelitian Sistem Informasi. Yogyakarta:Andi

[15] Chaou AK, Mekhaldi A, Teguar M (2015) Elaboration of novel image processing algorithm for arcing discharges recognition on hv polluted insulator model. IEEE Trans Dielectr Electr Insul 22:990-999

Fortin M, Battie MC. Quantitative paraspinal muscle measurements: inter-software reliability and agreement using OsiriX and ImageJ. Phys Ther. 2012;92(6):853-64 


\section{Biodata Penulis}

Yeka Hendriyani, Lahir di Tungkal, 20 Mei 1984. Sarjana Teknik Komputer dan Magister Komputer diperoleh dari Universitas Putera Indonesia, YPTK Padang. Sekarang dosen pada Program studi Pendidikan Teknik Informatika Fakultas Teknik Universitas Negeri Padang 